UDC 811.112 .5

\title{
Jacek Karpiński
}

Universiteit van Wrocław, Poland

\section{TAAL VAN NEDERLANDSE INDOOR CYCLING INSTRUCTEURS}

For citation: Karpiński J. Taal van Nederlandse indoor cycling instructeurs. Scandinavian Philology, 2021, vol. 19, issue 1, pp. 30-41. https://doi.org/10.21638/11701/spbu21.2021.102

Sport, beweging, lichamelijke conditie en een goede gezondheid zijn voor veel mensen over de hele wereld belangrijk. Juist om deze reden ontstaan er steeds nieuwe fitnesscentra, die hun klanten een grote waaier van verschillende activiteiten (o.a. krachtraining, personal training of groepslessen) aanbieden. Een van de meest populaire fitnessvormen is sinds jaren indoor cycling - een groepsles op stationaire fietsen in het ritme van aansporende muziek. Een charismatische trainer hoort daar natuurlijk ook bij. In dit artikel wordt andacht besteed an de specifieke taal van Nederlandse indoor cycling instructeurs, die gebruikt wordt in contact met hun klanten. Het onderzoek baseert op de participerende observatie van Spinning ${ }^{\circ}$-lessen in Nederlandse fitnesscentra in de periode juni 2019-maart 2020 en wordt aangevuld met eigen ervaring als indoor cycling instructeur. Al op het eerste gezicht ziet men duidelijke kenmerken, die deze taal bijzonder maken, o.a. een karakteristieke uitspraak en intonatie, woordenschat, enkele morfosyntactische eigenaardigheden of het gebruik van affirmatie en visualisatie. De taal is een belangrijk instrument om de balans tussen lichaam en geest te waarborgen. Bovendien wordt de taal gezien als een deel van de hele filosofie van Spinning ${ }^{\circ}$, wat de woorden van Johnny G., de bedenker van dit programma, bevestigen: „Spinning" has always shone a bright light in the health and fitness community. Not because riding a stationary bike is such a trick, but because of its language".

Sleutelwoorden: Nederlandse taal, indoor cycling, Spinning ${ }^{\circledR}$, vaktaal, taal van instructeurs, visualisatie, affirmatie.

\section{INLEIDING}

Tegenwoordig speelt een goede conditie en fitness een belangrijke rol in het leven van een doorsnee mens. Fit zijn is voor velen een begeerlijke eigenschap gebleken. De hele fitness sector blijft daarom constant 
doorgroeien. Uit het onderzoek van BlackBoxPublishers, NL Actief en Life Fitness Benelux [Wolfhagen, Middelkamp, 2019] blijkt dat er in Nederland ca. 2000 fitnessclubs zijn, waar wekelijks 3 miljoen Nederlanders van $12 \mathrm{t} / \mathrm{m} 79$ jaar aan fitness doen. Een populaire fitnessvorm is indoor cycling - een groepsles op stationaire fietsen met een charismatische instructeur die niet alleen vertelt welke oefeningen men moet doen maar vooral - via zijn taalgebruik en keuze van inspirerende muziek - de groep motiveert en voor een beetje entertainment zorgt. Het toonaangevende programma van indoor cycling is Spinning ${ }^{\oplus 1}$, dat in de jaren 90 van de $20^{\text {ste }}$ eeuw in de VS is ontwikkeld en in de loop der tijd de hele wereld heeft veroverd. Al na de eerste minuten van de training kan men opmerken dat de taal gebruikt door de indoor cycling instructeurs in vele aspecten verschilt van de taal gebruikt door instructeurs van andere fitnessvormen.

Het doel van dit artikel is te tonen, wat de kenmerken van deze taal zijn en welke functie ze hebben. Om het antwoord op deze vraag te vinden wordt een onderzoek in vorm van participerende observatie [Angrosino, 2010] van Spinning ${ }^{\circledR}$-lessen in verschillende Nederlandse fitnesscentra in de periode juni 2019-maart 2020 uitgevoerd. Als lid van de groep en actief deelnemer heeft men directe toegang tot de lessen en nauw contact met zowel de instructeurs als andere cursisten. De resultaten worden aangevuld met eigen ervaring als Spinning ${ }^{\circledR}$-instructeur in de jaren 2011-2017.

Bij dit onderzoek gaat men van de antropocentrische theorie van vaktalen uit. S. Grucza [Grucza, 2010, p. 46] betoont de prominente positie van mens in het linguïstisch onderzoek: „Przedmiot lingwistyki zajmującej się rzeczywistymi językami konstytuują konkretni ludzie, którymi interesuje się ona ze względu na ich konkretne właściwości (umiejętności) językowe" [Het onderwerp van de linguïstiek die zich bezighoudt met reële talen wordt gevormd door concrete mensen in wie ze geïnteresseerd is vanwege hun concrete linguïstische eigenschap-

${ }^{1}$ De oorsprong van Spinning ${ }^{\circledR}$ gaat terug tot het jaar 1987 toen de Zuid-Afrikaanse lange afstandfietser - Jonathan Goldberg (beter bekend als Johnny G.) - in de VS de eerste spinningfiets bouwde om thuis te trainen. In 1993 worden in sportscholen in New York de eerste lessen volgens de Spinning ${ }^{\oplus}$-filosofie gegeven en pas later wordt deze fitnessvorm in Europa geïntroduceerd [https://spinning.eu]. Ze groeide in de loop der jaren uit tot een toonaangevend indoor cycling programma met nu talrijke fitnesscentra in meer dan 80 landen, 250.000 gecertificeerde instructeurs ter wereld en meer dan 25 talen waarin men lessen kan volgen [https://spinning.eu]. 

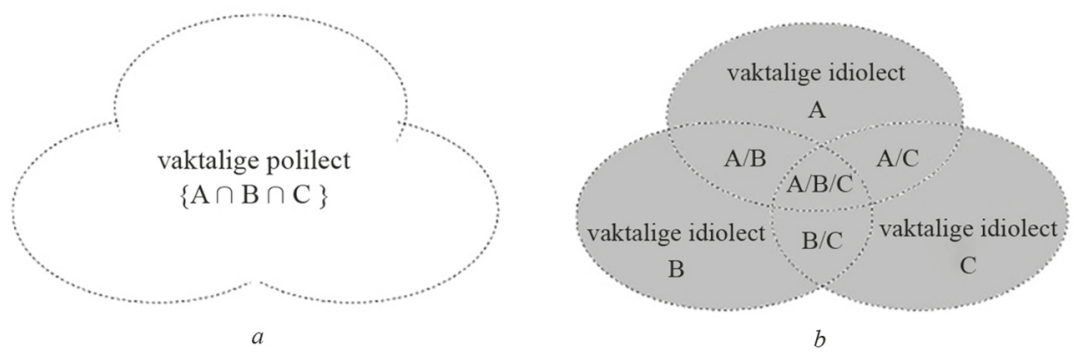

afb. 1 - Vaktaal als polilectale constructie $(a, b)$ [S. Grucza, 2010, p. 51], aangepast door JK

pen (vaardigheden) - vert. JK]. Vanuit het antropocentrisch perspectief kunnen alle vaktalen gekarakteriseerd worden als polilectale constructies [F. Grucza, 1994; Grygoruk, 2008; S. Grucza, 2010; OlpińskaSzkiełko, 2016; Osiejewicz, 2016], d.w.z. dat de taal van indoor cycling instructeurs een som is van idiolecten van verschillende trainers en tegelijkertijd hun logische doorsnede (afb. 1).

Men moet zich er dus van bewust zijn dat iedereen anders is en iedereen zijn eigen idiolect gebruikt. Er zijn echter enkele gemeenschappelijke kenmerken in deze idolecten, die beschouwd kunnen worden als eigenschappen van de hele vaktaal - de taal van indoor cycling instructeurs.

\section{TAAL VAN INDOOR CYCLING INSTRUCTEURS}

Johnny G. ging al vanaf het begin van het hele trainingprogramma daarvan uit, dat de taal van instructeurs een van de belangrijkste factoren tijdens de lessen is. Hij merkte op dat: „Spinning has always shone a bright light in the health and fitness community. Not because riding a stationary bike is such a trick, but because of its language. It is this language that inspires each Energy Zone ${ }^{\mathrm{TM}}$, each time we use it" [Mad Dogg Athletics, 2006, p. 1]. Het grote belang van de taal in het programma is ook zichtbaar in het feit dat er verschillende cursussen en workshops voor de trainers worden georganiseerd waar het fenomeen taal centraal staat. Een voorbeeld daarvan is de cursus Spinning Language and Visualization:

Learn to communicate and coach effectively with descriptive images and metaphors that promote greater energy, confidence, focus and ability. You'll be 
able to tap into your students' senses with vivid imagery and evoke an emotional response to jump-start their thinking — and your classes [https://spinning.eu].

Tijdens deze cursus wordt aandacht besteed aan de juiste communicatie tussen instructeur en deelnemers, efficiënte en effectieve coachingstechnieken en het gebruik van beeldspraak, affirmatie en visualisatie tijdens de lessen. Besproken worden ook verschillende methodes om via de taal emoties bij de deelnemers op te roepen. Met behulp van diverse hulpmiddelen kunnen instructeurs hun eigen taal creëren die deelnemers motiveert, wat voor het hele programma essentieel is. Mad Dogg Athletics [Mad Dogg Athletics, 2006, p. 1] gaat daarvan uit, dat „[y]our language and words can plant the seed for students to become more physically and mentally conditioned". Bovendien moet men zich ervan bewust zijn dat het lichaam zijn fysieke grenzen heeft maar het potentieel van de geest grenzeloos is [vgl. Mad Dogg Athletics, 2006, p. 28]. De juiste mentale instelling kan dus helpen fysiek succes te behalen.

Het uitgevoerde onderzoek (zie hoofdstuk 1) heeft bewezen dat er specifieke kenmerken zijn van het taalgebruik van Nederlandstalige Spinning ${ }^{\circledR}$-instructeurs. Ze zijn zichtbaar zowel op fonologisch en morfosyntactisch niveau, alsook in de woordenschat. Herkenbaar zijn o.a. verschillende prosodische elementen (ritme, intonatie, toon, pauzes), specifieke woordenschat (vaktalige terminologie, anglicismen, zintuiglijke werkwoorden, 'power words', metaforen, vergelijkingen, affirmaties, visualisaties) en morfosyntactische eigenaardigheden (losse woorden, enkelvoudige zinnen, vragen, het gebruik van presens en imperatief).

\subsection{Prosodische elementen}

De intonatie van Spinning ${ }^{\circledR}$-instructeurs is heel vaak afgestemd op muziek die het ritme, tempo en timing bepaalt. Elke verandering in het ritme van muziek en spraak verhoogt ook de dynamiek van de les. Kalmerende deuntjes bij de warm up of bij het rusten aan het einde van de training gaan meestal samen met de kalme stem van de trainer. Op momenten van zwaardere workout en een duidelijkere beat in de speakers, wordt de stem van de instructeur ook duidelijker en luider. Met behulp van de intonatie kan de instructeur zijn groep aanmoedigen om nog harder te werken. Op deze nauwe relatie tussen muziek en de stem van de trainer wijst ook Johnny G. in een interview voor WebMD: „[w]ith 
the voice of the instructor and having the backdrop of music, you have so many possibilities and opportunities to either train with the music, or use the music as an inspirational pad, where the instructor can go into language patterns, dealing with emotions and thoughts, and how you can engage yourself" [Spinning: The Mind \& Body Experience with Johnny G.].

Van belang lijken ook andere prosodische elementen van de taal gebruikt door de instructeurs zoals bijv. toon, klemtoon en pauzes. Door het gebruik van hoge en lage tonen kunnen gemakkelijker emoties worden uitgedrukt. Kenmerkend voor de instructeurs is ook het klemtoon leggen op kwesties die op een bepaald moment essentieel zijn - of het om water drinken gaat, weerstand hoger instellen, zich iets voorstellen, een handpositie veranderen of een andere oefening doen. Pauzes maken ook deel uit van de karakteristieke prosodie van de instructeurs. Door te pauzeren kan men meer aandacht besteden aan de inhoud van de meegedeelde informatie. Daarnaast bieden momenten van stilte de deelnemers de gelegenheid om zich op hun workout te concentreren.

Opgemerkt moet ook worden dat de instructeurs nooit schreeuwen. Hun stem zorgt altijd voor concentratie op de training.

\subsection{Woordenschat}

Op het lexicale niveau ziet men zonder twijfel de meeste karakteristieke eigenschappen van de taal van indoor cycling instructeurs. Het is niet verbazingwekkend dat de vakterminologie beslist op de voorgrond staat. Met behulp van de specialistische woordenschat worden bepaalde activiteiten kenmerkend voor het Spinning ${ }^{\circledR}$-programma duidelijk beschreven en informatie over de training verstrekt. De meeste vakbegrippen, die gebruikt worden, zijn vooral verbonden met anatomie en fysiologie van de training:

Knieën een beetje warm maken, enkels, heup...

Je hartslag natuurlijk een klein beetje omhoog brengen zodat de calorieverbranding ook gaat werken

Zo meteen lekker zweten

Hartslag schiet omhoog

Als je geen hartslagmeter hebt, is je ademhaling een goede graadmeter. 
Regelmatig worden verschillende rijtechnieken aangehaald. De pijlers van het programma zijn namelijk 3 verschillende handposities en 9 bewegingen (oefeningen), o.a. zittend fietsen, staand fietsen, spurten of klimmen. Een zeer belangrijk en nuttig instrument is een hartslagmeter, die de deelnemers in staat stelt de intensiteit van de training te controleren. Bovendien stelt men individueel de weerstand in, die aangepast is aan eigen uithoudingsvermogen. Er wordt dus aandacht ook besteed aan de gewenste trapfrequentie (cadans) of aan de hartslag, die men van de hartslagmeter kan aflezen:

\author{
RPM 70 \\ Hartslag $75 \%$ \\ Handen in drie \\ Zo meteen weerstand in de plus, omhoog \\ Handen als je hebt, in het midden van het stuur
}

Het Spinning ${ }^{\circledR}$-programma baseert op vijf 'energy zones': recovery (herstel), endurance (basis uithouding), strength (kracht), interval en race day. Om deze reden komen ze ook vaak in de taal van de instructeurs naar voren:

Vandaag werken we aan onze kracht $-75 \%-85 \%$ van de maximale hartslag. Dit is een uitdaging voor het sterke hart - Race Day!

Intervallen zijn als plezier en pijn.

Men mag niet vergeten dat de verbinding tussen lichaam en geest tijdens de lessen essentieel is. Een goed middel om dat te bereiken is visualisatie. Sage [2019] merkt op: „Indoor cycling classes are the perfect theater for using creative imagery in coaching. Since we are riding bikes that go nowhere, the use of visualization techniques becomes necessary to break through those four walls enclosing the room, and is one of the unique aspects that sets indoor cycling apart from so many other group fitness classes". Met visualisatie is het bovendien mogelijk de rechterhersenhelft aanzienlijk te stimuleren, wat positieve effecten kan hebben voor de hele workout. Vaak zorgt het ook voor een betere sfeer tijdens de les en meer engagement van de deelnemers:

Langs de camping, langs de rivieren, het gebergte in!

Ons pad wordt moeilijker en moeilijker. Je rijdt langzaam het zand in. Voel de weerstand die het je oplevert. Probeer dit tempo te houden en schakel weerstand bij. 
Vandaag neem ik jullie mee op een reis naar Fuerteventura. Het zal hard waaien, er zullen bergen zijn, maar we gunnen ons ook een moment van ontspanning op het strand in Morro Jable.

Omdat muziek een belangrijke rol speelt tijdens de training en zowel het ritme als de gewenste cadans bepaalt, verwijzen de instructeurs heel vaak naar de elementen van de gespeelde muziek - melodie, lyrics, sfeer:

Als je goed naar de muziek luistert, hoor je de heartbeats. Luister ook naar je hart! Close your eyes. Just feel and realize... Doe precies hetzelfde. Doe je ogen dicht! Wat voel je?

Luister naar de muziek. Hoor en voel het ritme. Laat je benen precies hetzelfde ritme slaan.

Kenmerkend voor de taal van indoor cycling instructeurs zijn ook verwijzingen naar alle zintuigen - zien, horen, ruiken, proeven en voelen. De deelnemers zijn dan min of meer verplicht om met alle zintuigen de omringende realiteit waar te nemen:

Kijk om je heen. Wat zie je? Bergen? Rivieren? Blijf daar. Doe je ogen dicht. Luister naar je hart, luister naar je adem... Relax!

Lekker klimmetje komt eraan. Voel een voorproefje van deze berg. Schakel een klein beetje weerstand bij. Niet in één keer volle bak.

Met de zintuigen zijn ook talrijke emoties verbonden. Mad Dogg Athletics [2006, p.2] betoont het belang van emoties en de zgn. 'power words': „The realization of love, peace, balance and happiness amplify and nurture the Spinning journey". De deelnemers wordt bovendien vaak verzocht om binnen hun eigen lichaam te kijken of om leuke herinneringen in hun hoofden op te halen. Het opwekken van positieve emoties is dus een vast onderdeel van de indoor cycling lessen:

Het is tijd om verliefd te worden op deze heuvel.

De zon schijnt recht in je gezicht. Het wordt steeds warmer en warmer. Leuk zo!

Denk aan wat je vandaag al hebt gedaan. Wat is je al gelukt? Good job!

Kenmerkend voor de taal van indoor cycling instructeurs zijn ook talrijke metaforen en vergelijkingen. Het gebruik van deze elementen helpt om de verbinding te zien tussen de workout op de fiets en andere 
activiteiten in het dagelijks leven. Op deze manier zijn de deelnemers geconfronteerd met iets, wat hen al goed bekend is en wat men zich tijdens de training kan voorstellen en met succes toepassen:

Als het leven obstakels voor je plaatst, spring er dan overheen.

Klim naar de top van deze berg net zoals je elke dag klimt voor je succes.

Race Day is zoals spelen met dynamiet.

Een belangrijk kenmerk van de woordenschat van indoor cycling instructeurs is het gebruik van affirmaties. Het doel daarvan is de deelnemers positief over zichzelf te laten denken, maar ze ook te inspireren en hen kracht te geven. Affirmaties wekken bovendien het lichaam op om een hoger prestatieniveau te bereiken, wat in fitness en sport essentieel is:

Mooi zo. Goed zo.

Ik kan mijn energie verhogen.

Je kan dat doen. Niet stoppen. Blijf rustig doortrappen.

Vermeldenswaard is ook het feit dat er in de taal van indoor cycling instructeurs veel anglicismen voorkomen. Heel vaak gaat het om de namen van de oefeningen, bijv. seated flat, standing climb, sprints, jumps, de namen van de 'energy zones', bijv. strength, endurance, race day en om vaste onderdelen van de workout zoals bijv. warm up of cool down. Soms voegen de trainers ook hele zinnen (of delen daarvan) in het Engels:

Vier, drie, twee, staan. Go!

Easy in de zadel

We klimmen nu deze berg op. Het tempo stijgt ook iets. Are you ready?

\subsection{Morfosyntactische kenmerken}

Hoewel woordenschat het meest opvallend is, mag men andere aspecten van de taal, die ook deel uitmaken van een bepaalde vaktaal, niet over het hoofd zien. In de taal van indoor cycling instructeurs zijn er enkele morfosyntactische kenmerken zichtbaar, die regelmatig worden gebruikt. Heel vaak grijpen trainers naar losse woorden in plaats van naar zinnen. Op deze manier kunnen ze bepaalde informatie en associaties heel snel en duidelijk aan de deelnemers overbrengen. 
Bovendien moet men niet over de hele structuur van de zin denken want er is in principe geen tijd en geen behoefte voor:

\section{Trainen, hard werken, conditie, gezondheid \\ Ritme. Adem. Cadans. Weerstand. \\ Klein tikkie terug}

Dezelfde functie als losse woorden vervullen ook enkelvoudige zinnen, die regelmatig aan bod komen. Ook bij visualisaties worden bijna geen samengestelde zinnen gebruikt. De bedoeling van de training is niet de ontcijfering van de overgebrachte boodschap of relaties tussen de zinnen te zoeken. Het gaat vooral om snelle en duidelijke instructies:

Kijk even naar rechts.

Verander je cadans met het ritme van de muziek.

Dit is een uitdaging voor je. Je kan het aan!

Omdat de trainers in eerste instantie instructies geven en deelnemers stimuleren om hun workout zo goed mogelijk te doen, gebruiken ze heel veel imperatieven:

\section{Dans op de pedalen! \\ Hou dit tempo vast! \\ Trap door, trap door!}

De training vindt plaats in het hier en nu. Daarom wordt vooral het presens gebruikt:

Je vooruitgang begint $n u$.

Als je staat is het belangrijk dat je voldoende weerstand hebt.

Als je naar links kijkt, zie je een mooi meer. Laten we daar een beetje uitrusten.

Af en toe hoort men zinnen in de verleden tijd maar in de meeste gevallen gaat het dan om het terughalen van bepaalde gebeurtenissen uit het verleden naar de geheugens van de deelnemers:

Nog maar een maand geleden was het een uitdaging voor je. Nu niet meer.

Vorige week hadden we een intervaltraining.

Herinner je je de laatste keer dat je een obstakel moest overwinnen?

En het lukte wel! 
Een ander kenmerk van de taal van indoor cycling instructeurs zijn retorische vragen. Het antwoord van de deelnemers is helemaal niet aan de orde, maar de bedoeling is de hersenen te stimuleren en gedachten op een doel te focussen. Mad Dogg Athletics [2006, p. 16] voegt hier nog toe: „The purpose of asking questions is to encourage students to seek the correct answers, which engages the brain and focuses the thoughts":

Wanneer was de laatste keer dat je iets alleen voor jezelf deed? Nu heb je de kans! Er ligt een hoge berg voor je. Wat doe je?

Klaar voor nog één interval?

\section{CONCLUSIES}

De taal gebruikt door de instructeurs tijdens de lessen speelt een belangrijke rol in het Spinning-programma. Actieve deelname aan de indoor cycling lessen in Nederland en jarenlange ervaring als Spinning ${ }^{\oplus}$ instructeur heeft de observatie van deze taal mogelijk gemaakt. Grondige analyse daarvan heeft bewezen dat er inderdaad wezenlijke kenmerken zijn, die de taal van indoor cycling instructeurs bijzonder maken.

Op fonetisch niveau zijn de eigenaardigheden vooral zichtbaar in de prosodie. Toon, intonatie, klemtoon, ritme en pauzes worden vooral gebruikt om belangrijke informatie te beklemtonen, aandacht te schenken aan bepaalde woorden, sfeer tijdens de les te creëren en deelnemers tot werken aan te moedigen.

De gebruikte woordenschat dient vooral voor verstrekking van duidelijke instructies en voor motivatie. Vaktalige begrippen zijn vooral verbonden met anatomie en fysiologie, maar ook met karakteristieke elementen van het Spinning -programma, zoals bijv. werken met een hartslagmeter. Een belangrijke rol spelen verschillende 'power words' zoals bijv. liefde, geluk of balans, zintuiglijke werkwoorden, affirmaties en visualisaties. Dankzij het gebruik van deze elementen wordt de verbinding tussen lichaam en geest tijdens de workout mogelijk gemaakt. Van belang lijkt ook het feit dat zowel de linker- als rechterhersenhelft tijdens de les wordt geactiveerd. Terwijl de linkerhersenhelft zich concentreert op de juiste techniek en naar mogelijkheden zoekt om de instructies in praktijk toe te passen, denkt rechterhersenhelft met beelden, visualiseert woorden van de instructeur en werkt met emoties. Positieve gevoelens ondersteund door sfeervolle muziek hebben ook hun vaste plaats gevonden in het hele programma. Men moet ook het feit 
betonen dat er veel Engelse woorden en uitdrukkingen worden gebruikt tijdens de lessen. Dit is aan de ene kant verbonden met de Amerikaanse oorsprong van Spinning (bijv. namen van oefeningen) en aan de andere kant met de overheersende rol van het Engels in het dagelijks leven.

Op het morfosyntactische niveau zijn de specifieke kenmerken van de taal van indoor cycling instructeurs ook zichtbaar. Het gebruik van losse woorden en korte, eenvoudige zinnen heeft als doel een snelle en duidelijke informatieoverdracht, maar het laat de deelnemers ook focussen op de eigen workout. Karakteristiek zijn ook talrijke imperatieven, zinnen in presens en rhetorische vragen. De instructeurs helpen op deze manier de deelnemers hun fysieke en mentale activiteiten met elkaar te verbinden, zich te verdiepen in eigen emoties, kracht en uithoudingsvermogen te vinden en als eindeffect talrijke training benefits te bereiken.

\section{REFERENCES}

Angrosino M. Badania etnograficzne i obserwacyjne. Warszawa: Wydawnictwo Naukowe PWN, 2010. 187 s.

Grucza F.O językach specjalistycznych (=technolektach) jako pewnych składnikach rzeczywistych języków ludzkich. Języki specjalistyczne. Eds. F. Grucza, Z. Kozłowska. Warszawa: Akapit, 1994. S.7-27.

Grucza S. Główne tezy antropocentrycznej teorii języków. Lingwistyka Stosowana, nr 2. Warszawa: Warszawska Drukarnia Naukowa PAN, 2010. S.41-68.

Grygoruk A. Terminologia - język — wiedza w tłumaczeniu tekstów specjalistycznych (na podstawie tekstów podatkowych i okołopodatkowych). Linguodidactica, Tom XII. Eds R. Hańczuk. Białystok: Wydawnictwo Uniwersytetu w Białymstoku, 2008. S. 19-30.

Mad Dogg Athletics. Spinning Language \& Visualisation. Workshop Outline. Venice: Mad Dogg Athletics, 2006. $27 \mathrm{s.}$

Olpińska-Szkiełko M. Anthropozentrische Sprachtheorie und Fachsprachenforschung. Lingwistyka Stosowana, 18. Eds. P. Bąk, B. Rolek. Warszawa: Instytut Komunikacji Specjalistycznej i Interkulturowej UW, 2016. S. 81-90.

Osiejewicz J. Fachsprache(n) im Lichte der anthropozentrischen Sprachentheorie. Fachsprachenforschung in Polen. Eds. K. Nycz, K.-D. Baumann, H. Kalverkämper. Berlin: Frank \& Timme, 2016. S. 65-76.

Sage J. Creative Visualization and Imagery, Part 1: The Power of Visualization, 2019. Available at: https://www.indoorcyclingassociation.com/creative-visualization-and-imagery-part-1/ (accessed: 28.04.2021).

Spinning. Available at: https://spinning.eu (accessed: 28.04.2021).

Spinning: The Mind \& Body Experience with Johnny G. Available at: https://www. medicinenet.com/script/main/art.asp?articlekey=53946 (accessed: 28.04.2021). 
Wolfhagen P., Middelkamp J. Fitness markt \& trend Rapport 2018-2020. Waalwijk: BlackBoxPublishers, 2019. $102 \mathrm{~s}$.

Jacek Karpiński

University of Wrocław, Poland

THE LANGUAGE OF DUTCH INDOOR CYCLING INSTRUCTORS

For citation: Karpiński J. The language of Dutch indoor cycling instructors. Scandinavian Philology, 2021, vol. 19, issue 1, pp. 30-41. https://doi.org/10.21638/11701/spbu21.2021.102 (In Dutch)

Sports, physical fitness and good health are important to most people across the world. For this reason, fitness centres are constantly growing and offering their customers a wide range of different activities (e. g., strength training, personal training or group classes). One of the most popular forms of fitness for years has been indoor cycling - a group class on stationary bikes to the rhythm of stimulating music. A charismatic trainer is of course a part of it. This article focuses on the specific language of Dutch indoor cycling instructors used in contact with their clients. The research is based on the participant observation of Spinning ${ }^{\circledR}$ classes in Dutch fitness centres between June 2019 and March 2020 and is supported with my own experience as an indoor cycling instructor. Already at first sight, some characteristics are noticeable that make this language special, such as specific pronunciations and intonations, vocabulary, certain morphosyntactic features or the use of affirmation and visualization. Language seems to be an important tool to ensure the balance between body and mind. Moreover, language is seen as part of the whole philosophy of Spinning ${ }^{\circledR}$, which confirms the words of Johnny G., the creator of this programme: "Spinning ${ }^{\mathbb{B}}$ has always shone a bright light in the health and fitness community. Not because riding a stationary bike is such a trick, but because of its language".

Keywords: Dutch language, indoor cycling, Spinning ${ }^{\circledR}$, language for special purposes, language of instructors, visualization, affirmation.

\section{Jacek Karpiński}

University of Wrocław, 21-22, Kuźnicza st., Wrocław, 50-138, Poland

E-mail: jacek.karpinski@uwr.edu.pl

Received: March 3, 2021

Accepted: April 26, 2021 